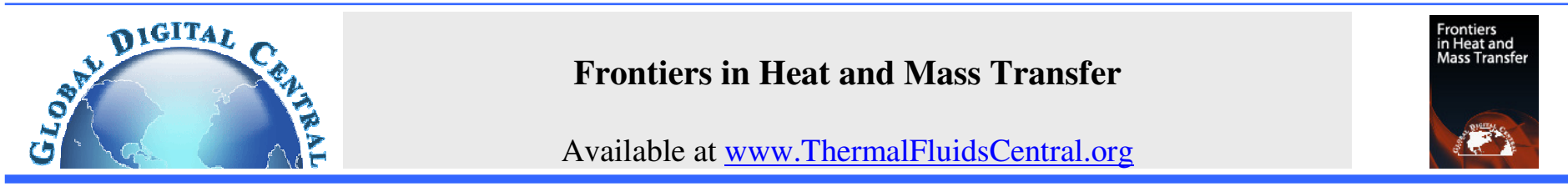

\title{
CFD INVESTIGATIONS OF THERMAL AND DYNAMIC BEHAVIORS IN A TUBULAR HEAT EXCHANGER WITH BUTTERFLY BAFFLES
}

\author{
Alem Karima ${ }^{\mathrm{a},{ }^{*}}$, Sahel Djamel ${ }^{\mathrm{b}}$, Nemdili Ali ${ }^{\mathrm{c}}$, Ameur Houari ${ }^{\mathrm{d}}$ \\ a, Faculté de Mécanique, Laboratoire de Carburants Gazeux et Environnement, USTO.MB, ALGERIA, BP 1505, El-M'Naouer, Oran 31000, Algeria \\ ${ }^{b}$ Département des Sciences Techniques, Faculté de Technologie, Université Amar Telidji-Laghouat, Algeria \\ ${ }^{c}$ Department of Hydraulics, Faculty of Architecture, USTO.MB, ALGERIA, BP 1505, El-M'Naouer, Oran 31000, Algeria \\ ${ }^{d}$ Institute of Science and Technology, University Center Salhi Ahmed, BP 66, 45000 Naâma, Algeria.
}

\section{ABSTRACT}

In the present paper, the effects of a new baffle design on the efficiency of a tubular heat exchanger are numerically investigated. It concerns butterfly baffles inserted in a cylindrical tube heat exchanger. We focus on the influence of the shape of baffles, the space between baffles (pitch ratio, PR) and the baffle size (i.e. the blockage ratio, BR) on the heat transfer and flow characteristics. Three geometrical configurations with different PRs are realized $(\mathrm{PR}=1,2$ and 4$)$ and five others with different blockage ratios $(\mathrm{BR}=0.1,0.2,0.3,0.4$ and 0.5$)$. The investigations are achieved for Reynolds numbers ranging from 3000 to 8000 . All analyses are realized with the help of the CFD Fluent software. The numerical results are compared with available experimental data and a satisfactory agreement is found. The obtained results showed that the butterfly baffle with PR $=4$ and $\mathrm{BR}=0.1$ is the best design that ensures the best flow mixing and increases the thermal enhancement factor by about 1.7 time with a moderate pressure drop.

Keywords: Tubular heat exchanger; Butterfly baffles; Heat transfer; Fluid flow; pressure drop

\section{INTRODUCTION}

A heat exchanger with a reduced cost, a compact size and with high thermal performance is very required in many engineering systems such as nuclear central, vehicle, refrigeration, solar air heater and several chemical engineering processes. Hence, the heat exchanger design plays a great challenge to overcome the problems of the lower performance. A successful technique for enhancing the heat transfer performance is using baffles/ribs or vortex generators (VGs). The presence of baffles helps to stop the thermal and hydrodynamic boundary layers and intensifies the turbulent flows. However, the use of baffles augments not only the heat transfer coefficient but also it increases significantly the pressure drop.

Until present, studies continue to optimize the design of baffles. Some researchers interested to the baffling in channels for different industrial applications such as for the solar energy applications Promvonge et al. (2011) and Kumar, Kim (2015), gas turbine cooling Giovanni (2004), sedimentation tanks Al-Sammarraee et al. (2009) and Asgharzadeh et al. (2011). Among others. In experimental studies, Han et al. (1991),(1992) examined the heat transfer phenomenon in a square channel with different attack angles of ribs on two walls for the pitch ratio $(\mathrm{P} / \mathrm{e}=10)$ and the blockage ratio $(\mathrm{e} / \mathrm{D}=0.0625)$. They reported that the angled ribs with ' $\mathrm{V}$ ' shape have a great effect on the heat exchanger performance. Torii et al. (2002) used delta winglettype baffles in a fin-tube heat exchanger with rounded tubes and found a great improvement in heat transfer and a reduction in friction factor. Wang et al. (2002) studied experimentally the effect of baffles on the flow structure and heat transfer in a fin-and-tube heat exchanger. They obtained a decrement of pressure loss tend to 25-55\% compared with the flat fin arrangement.

The orientation angle of baffle has an important effect of the heat transfer execution and the inclined baffle may give an enhancement by more than 30\%, as reported by Promvonge et al. (2014). Depending on the blockage ratio (from 0.05 to 0.3), Promvonge et al. (2010) revealed that the baffles with $45^{\circ}$ attack angle increases the heat transfer coefficient from $150 \%$ to $850 \%$. In the same field, Kwankaomeng et al. (2010) tested numerically the effect of $30^{\circ}$ inclined baffles with different values of BR on the fluid flow and heat transfer. They showed that the $30^{\circ}$ angled baffles produce the vortex flows and augment significantly the heat transfer coefficient in the channel. However, the heat transfer increase as associated with important pressure drop ranging from 1 to17 times above the channel without baffles. The horse shoes baffles used by Promvonge et al. (2015) in tubular heat exchangers offered a considerable improvement of heat transfer coefficient tend to $92-208 \%$, but with an increase in the friction factor by about 1.76 to 6.37 times compared with the smooth tube, i.e. a thermal performance factor varied from 1.34 to 1.92 .

The perforated baffle is another significant topic in heat transfer execution like underlined it Islam et al. (2010) and Bhuiyan et al. (2016).In the goal to reduce the lower heat transfer areas (LHTAs) behind the baffle, Sahel et al. (2016) proposed a perforated baffle having a row of four holes placed at three different positions (the so called pores axis ratio (PAR)). From all cases studied by these authors ( $\mathrm{PAR}=0.190,0.425$ and 0.660$)$ the first case is found to be as the best one. This article presents a new baffle design for tubular heat exchangers. It concerns baffles with a butterfly shape. We explore the

*Corresponding Authors. Email: karima.alem@univ-usto.dz 
efficiency of the new suggested design by changing its size (i.e. the blockage ratio) and the space between baffles (i.e. the pitch ratio).

\section{FLOW AND BAFFLE GEOMETRY}

The geometry of the problem studied concerns a circular tube with butterfly baffles (Figs. 1 and 2). Air is used as a working fluid. The tube length (L) is equal to $1000 \mathrm{~mm}$ and its diameter (D) is set to 50 $\mathrm{mm}$. Effects of the baffle size (e) are investigated by realizing five geometrical configurations $(\mathrm{e}=5,10,15,20$ and $25 \mathrm{~mm})$ which correspond to the following values of the ratio e/D (the so called blockage ratio, $\mathrm{BR}=\mathrm{e} / \mathrm{D})$ : $0.1,0.2,0.3,0.4$ and 0.5 , respectively. Effects of the space between baffles (i.e. the pitch P) are also examined and three cases are considered, which are: $\mathrm{P} / \mathrm{D}=1,2$ and 4 . Extended regions were added at the inlet and the outlet sections of the tube to ensure the fully developed flow at the inlet and to avoid the appearance of reversed flows at the outlet.

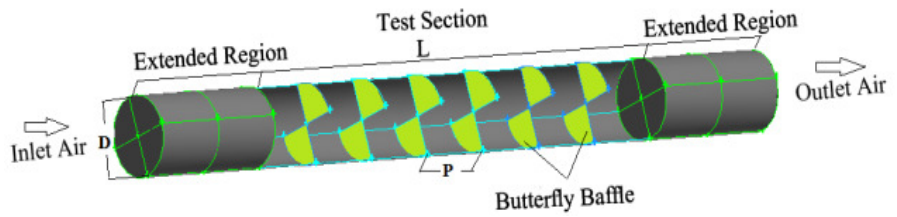

Fig. 1 Heat exchanger geometry

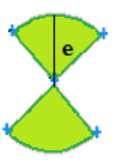

$\mathrm{BR}=\mathbf{0 . 1}$

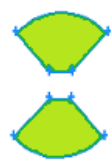

$\mathrm{BR}=0.2$

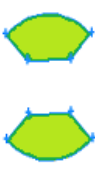

$\mathrm{BR}=\mathbf{0 . 3}$

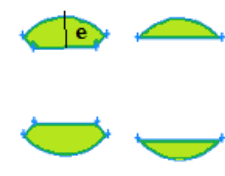

$B R=0.4 \quad B R=0.5$

Fig. 2 Geometry of the butterfly baffles

\subsection{Boundary Conditions}

The velocity and temperature profiles are identified at the inlet section. A uniform air velocity $\mathrm{U}=\mathrm{U}_{\text {in }}$ and a constant temperature $\mathrm{T}_{\text {in }}=300^{\circ} \mathrm{K}$ (corresponding to the Prandtl number Pr $=0.7$ ) were introduced at the inlet boundary, while an atmospheric pressure outlet condition was applied at the exit. The air physical properties are constants. No-slip wall condition is applied for the tube walls and the baffles. The temperature of all the tube walls is kept constant at $350^{\circ} \mathrm{K}$ while the baffles are assumed at adiabatic walls.

\subsection{Mathematical Formulation}

The duct flow is governed by the Reynolds averaged Navier-Stokes (RANS) equations and the energy equation. For incompressible turbulent flows these equations can be written as:

Continuity equation:

$$
\frac{\partial}{\partial x_{i}}\left(\rho u_{i}\right)=0
$$

Momentum equation:

$\frac{\partial}{\partial x_{i}}\left(\rho u_{i} u_{j}\right)=\frac{\partial}{\rho x_{i}}\left[\mu\left(\frac{\partial u_{i}}{\partial u_{j}}-\overline{\rho u_{i}^{\prime} \rho u_{j}^{\prime}}\right)\right]-\frac{\partial p}{\partial x_{i}}$

Energy equation:

$\frac{\partial}{\partial x_{i}}\left(\rho u_{i} T\right)=\frac{\partial}{\rho x_{i}}\left(\left(\Gamma+\Gamma_{t}\right) \frac{\partial T}{\partial x_{j}}\right)$

where $\Gamma$ is the thermal diffusivity, it is given by:
$\Gamma=\frac{\mu}{p_{r}}$

$\rho u_{i}^{\prime} u_{j}^{\prime}$ is the Reynolds stresses defined by The Boussinesq hypothesis (FLUENT, 2001):

$\overline{\rho u_{i}^{\prime} u_{j}^{\prime}}=\mu_{t}\left(\frac{\partial u_{i}}{\partial x_{j}}+\frac{\partial u_{i}}{\partial x_{i}}\right)-\frac{2}{3}\left(\rho k+\mu_{t} \frac{\partial u_{i}}{\partial x_{j}}\right) \delta_{i j}$

Where $\delta_{\mathrm{ij}}$ is the Kronecker delta.

The $\mathrm{k}-\varepsilon$ standard model of turbulence which is based on the turbulent kinetic energy $\mathrm{k}$ (Eq. 6) and the energy dissipation $\varepsilon$ (Eq. 7) is used in this study.

$$
\begin{aligned}
& \frac{\partial}{\partial x_{j}}\left(\rho k u_{i}\right)=\frac{\partial}{\partial x_{j}}\left[\left(\mu+\frac{\mu_{t}}{\sigma_{k}}\right) \frac{\partial k}{\partial x_{j}}\right]+G_{k}+\rho \varepsilon \\
& \frac{\partial}{\partial x_{i}}\left(\rho \varepsilon u_{i}\right)=\frac{\partial}{\partial x_{j}}\left[\left(\mu+\frac{\mu_{t}}{\sigma_{\varepsilon}}\right) \frac{\partial \varepsilon}{\partial x_{j}}\right]+C_{1 \varepsilon} \frac{\varepsilon}{k}-C_{2 \varepsilon} \rho \frac{\varepsilon^{2}}{k}
\end{aligned}
$$

In these equations, $\mathrm{G}_{\mathrm{k}}$ represents the turbulence kinetic energy generated by the mean velocity gradients.

The empirical constants for the are assigned the following values (FLUENT, 2001):

$\mathrm{C}_{\mu}=0.99 ; \mathrm{C}_{1 \varepsilon}=1.44 ; \mathrm{C}_{2 \varepsilon}=1.92 ; \sigma_{k}=1.0 ; \sigma_{\varepsilon}=1.3$

The standard k- $\varepsilon$ turbulence model is reliable and robust, with a higher convergence rate compared to other models, and it gives accurate results in the prediction of turbulent flow and heat transfer in the baffled channels (Promvonge et al 2010, 2014, 2015 and Sahel et al 2016).

The heat transfer is calculated from the Nusselt number $(\mathrm{Nu})$ which can be obtained by:

$N u=\frac{h D}{K_{f}}$

The Reynolds number $(\mathrm{Re})$ based on tube diameter is given by:

$R e=\frac{u D}{\mu}$

The friction factor (f) calculated along the test tube length $(\mathrm{L})$ is written as:

$f=\frac{2}{\left(L / D_{h}\right)} \frac{\Delta P}{\rho U_{\text {in }}{ }^{2}}$

The thermal enhancement factor $\eta$ is defined by:

$\eta=\left(N u / N u_{0}\right) /\left(f / f_{0}\right)^{1 / 3}$

Where $\mathrm{Nu}_{0}$ and $\mathrm{f}_{0}$ are the Nusselt number and friction factor for a smooth tube, respectively

\subsection{Numerical Method}

The geometry of the system examined was created and meshed by using the Gambit software. A tetrahedral mesh element is selected for meshing the computational domain (Fig. 3). In this field, we can choose any type of mesh. where the most important is the mesh sensitivity test which gives a high accuracy of results. In addition, the tetrahedral mesh is simple to generate in complex geometries. For the tube without baffles, mesh tests were realized with following series of grids: 487460, 594924, 766411, 882797 and 978575 mesh elements. The accuracy of results is obtained from 766411 elements, where the variations of the Nusselt number do not go above $2 \%$ with further increases in the grid density. Hence, the final grid number which is adopted for the following investigations is 766411 elements. The same strategy was used for the other geometrical arrangements, where the adopted grids element was varied from 844191 to 1040998 elements. 


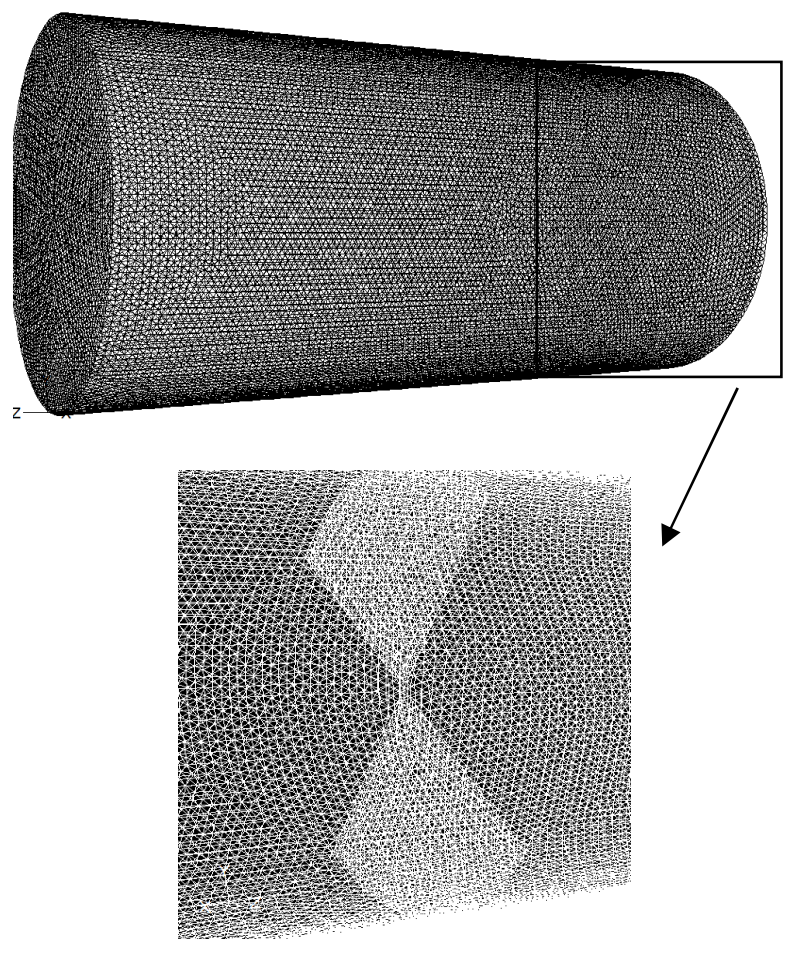

Fig. 3 Example of generated grid of tetrahedral type.

FLUENT (2001), which is based on the finite volume method, is the commercial software used to simulate the fluid flow and heat transfer in the computational domain. The flow regime is turbulent and the tube flow model is governed by the Reynolds averaged Navier-Stokes equation with the standard $\mathrm{k}-\varepsilon$ turbulence model and the energy equation.

Investigations are considered steady and the flow regime is turbulent. The second order scheme is employed to discretize the convective terms in governing equations. For the pressure-velocity coupling, the SIMPLE algorithm (Semi-Implicit Pressure Linked Equation) is used. Default under-relaxation factors of the solver are used to control the update of computed variables for each iteration. These factors are: $0.3,1,0.7$ and 1 for pressure, density, momentum and energy, respectively. The criterion of convergence is that the standardized residuals are below $10^{-6}$ for the flow equations and $10^{-9}$ for the energy equation.

Simulations were achieved in a computer with Intel core i7 including 6.0 GB of RAM and processor speed of $2.20 \mathrm{GHz}$. Convergence was obtained after 8000-14000 iterations with computational times of 4-6 hours.

\section{RESULTS AND DISCUSSION}

\subsection{Validation of Predicted Results}

The predicted results on the heat transfer and friction characteristics in a smooth tube are validated by checking the values of Nusselt number $(\mathrm{Nu})$ and friction factor (f). With the same geometrical and operating conditions, our results were compared with those obtained by using. the Dittus-Boelter's (1930) and Gnielinski's (1976) correlations for Nusselt number, Moody diagram (1944) and Gnielinski's correlation for the friction factor.

The Dittus-Boelter's correlation is:

$$
N u=0.023 \operatorname{Re}^{0.8} \operatorname{Pr}^{0.4} \text { For } \operatorname{Re} \geq 10000 \text {. }
$$

The Gnielinski's correlation is:

$$
\begin{aligned}
& N u=\frac{(f / 8) \operatorname{RePr}}{1+12.7(f / 8)^{1 / 2}\left(\operatorname{Pr}^{2 / 3}-1\right)} \\
& \text { For } \quad 2300 \leq \operatorname{Re} \leq 5.10^{6}
\end{aligned}
$$

The friction factor correlation from the Moody diagram is:

$$
f=0.316 R e^{0.25} \quad \text { For } \quad \operatorname{Re} \leq 2.10^{4}
$$

The friction factor given by the Gnielinski's Correlation is :

$$
f=(0.76 \ln R e-1.64)^{-2} \text { For } 2300 \leq \operatorname{Re} \leq 5.10^{6}
$$

Figs. $4 \mathrm{a}$ and $4 \mathrm{~b}$ present the variation of Nusselt number and the friction factor vs. Reynolds number, respectively. The comparison of our numerical results with the other data shows a satisfactory agreement. As shown in the figure, the correlations of Gnielinski (1976) is merit to use in the validation of both Nusselt number in the smooth tube. Where, the deviation between the numerical results and those predicted by Gnielinski (1976) do not less 3\% for the Nusselt number. For the friction factor prediction, both correlations of Gnielinski (1976) and Moody diagram (1944) give the same deviations of about $10 \%$.

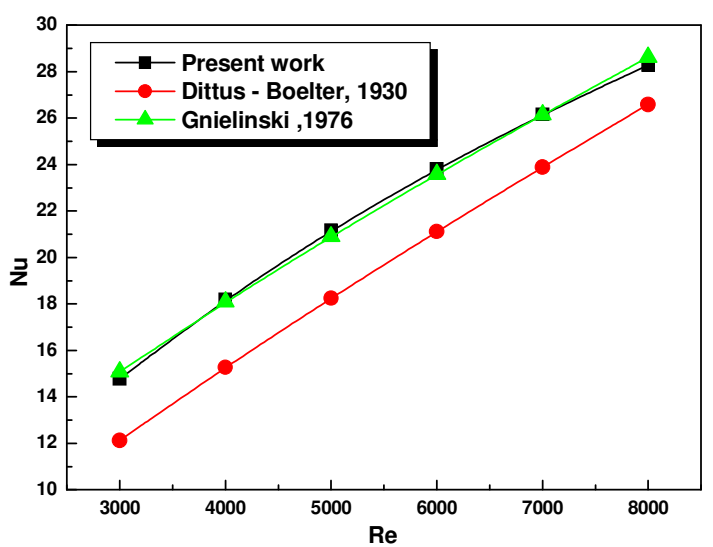

(a)

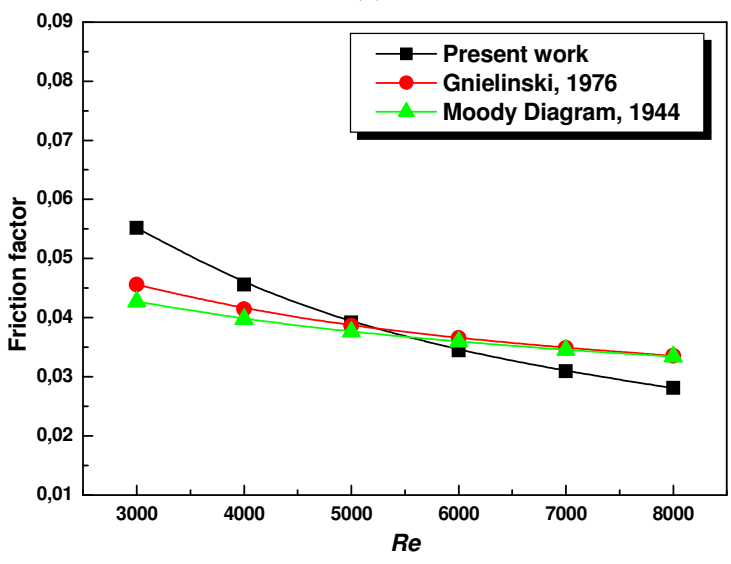

(b)

Fig. 4 Verification of (a) Nusselt number and (b) friction factor for a smooth tube 


\subsection{Flow Structure}

The flow modifications due to the presence of baffle inside the tubes give more augmentation in the heat transfer coefficient of the heat exchanger. For $\mathrm{BR}=0.4$ and $\mathrm{Re}=4000$, Fig. 5 (a-d) shows the temperature distribution in a smooth tube and for different pitch ratios $(P R=1,2$ and 4$)$. This figure clearly reveals the important change in the temperature along the tube walls, especially in the region behind the baffle, where recirculation zones are located. On the other hand, a weak temperature gradient is created in the other regions by swirling flows.

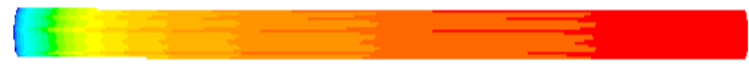

a)

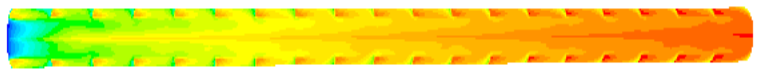

b)

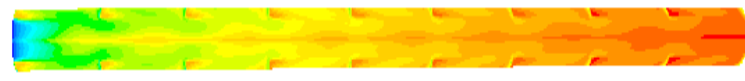

c)

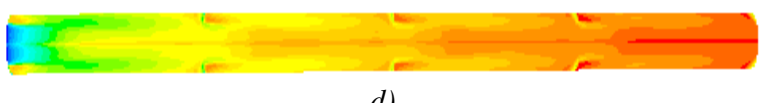

d)

Fig. 5 Temperature contours $\left[{ }^{\circ} \mathrm{K}\right]$ for (a) smooth tube, (b) $P R=1$, (c) $\mathrm{PR}=2$ and $(\mathrm{d}) \mathrm{PR}=4$, at $\mathrm{Re}=4000, \mathrm{BR}=0.4$

Fig. 6 presents the distribution of the axial velocity for different values of the pitch ratio ( $\mathrm{PR}=1,2$ and 4$)$, at $\mathrm{BR}=0.4$ and $R e=4000$. As reported in literature, the flow structures influence directly on the thermal performance of heat exchangers. Moreover, the presence of baffles in the tubes of heat exchangers is also an important technique to enhance the heat transfer coefficients where these baffles help to stop the thermal and hydrodynamic boundary layers and intensifies the turbulence and the fluctuation velocity near the tube wall.

It can be observed from Fig. 6 a-c that two pairs of counter rotating vortices, which are caused by the baffle, are located on the lower and upper parts of the channel. The appearance of vortices yields an increase in the heat transfer execution by the separation of the main flow on both sides of baffle, where swirling flows are produced. Furthermore, the sufficient space between two successive baffles with the butterfly form allows the formation of recirculation loops of fluid inside the tube. However, the impingement flow on the baffle and its separation on the baffle sides are responsible for the heat transfer improvement in the baffled tube like underlined it Zhang et al. (2009).

\subsection{Nusselt Numbers}

The variation of Nusselt numbers versus Reynolds numbers for different baffles arrangement is presented in Fig. 7. In order to optimize the heat transfer execution, two baffle configurations are tested: the pitch ratio $(\mathrm{PR}=1,2$ and 4$)$ and the blockage ratio $(\mathrm{BR}=$ $0.1,0.2,0.3,0.4$ and 0.5$)$.

Since the baffle creates swirling flows and intensifies the turbulence, the heat transfer coefficient for the baffled tube is generally higher than that for the smooth tube. In Fig. 4, the Nusselt number slightly increases with the increase of the pitch ratio (PR). Also, it clearly augments with the rise of the blockage ratio (BR) and Reynolds number $(\mathrm{Re})$. With the optimal value of pitch ratio $(\mathrm{PR}=1)$ and at $R e$ $=8000$, the heat transfer enhancements with the following values of the blockage ratio $(\mathrm{BR}=0.1,0.2,0.3,0.4$ and 0.5$)$ are about $27 \%, 29 \%$, $36 \%, 40 \%$ and $32 \%$ above the smooth tube, respectively.
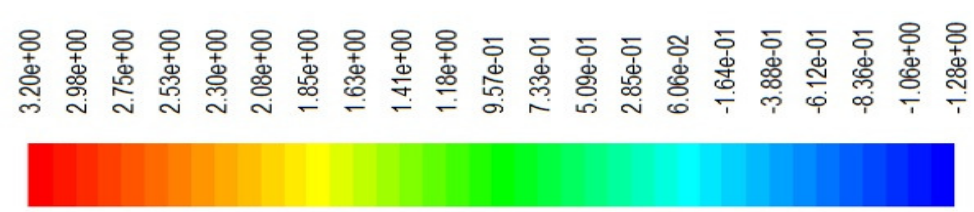

Vertical section<smiles>C1CCC1</smiles>

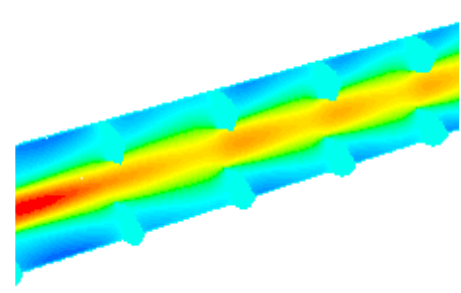

a)

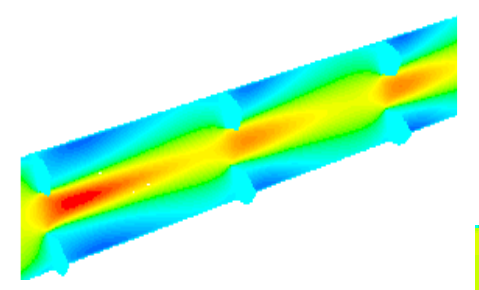

b)
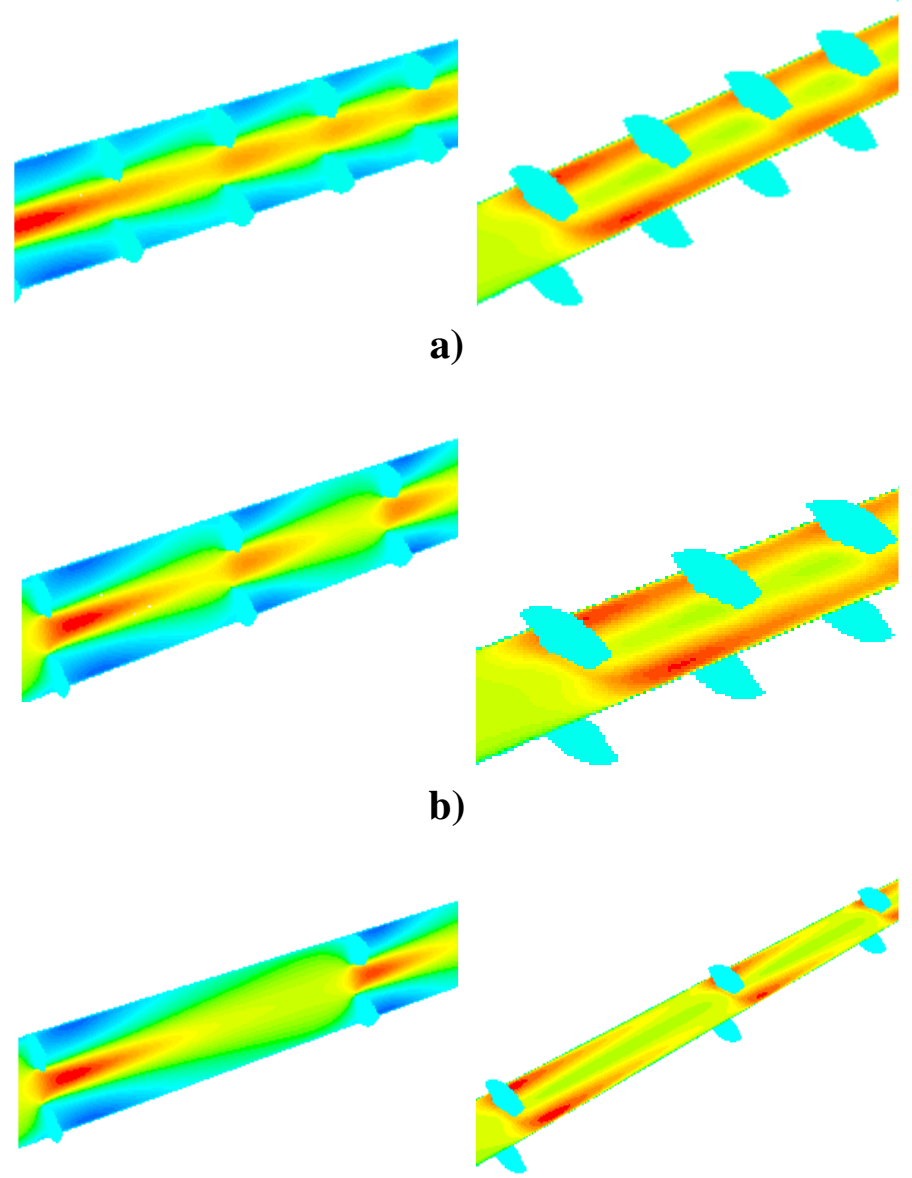

c)

Fig. 6 Axial velocity distribution (in $[\mathrm{m} / \mathrm{s}]$ ), for (a) $P R=1$ (b) $P R=2$, (c) $\mathrm{PR}=4$, at $\mathrm{Re}=4000$.

The higher heat transfer coefficient is obtained with the case $(\mathrm{BR}=$ $0.4, \mathrm{PR}=1$ and $R e=8000$ ), where the Nusselt number value for this case is higher by about $40 \%$, compared with the smooth tube. Hence, the heat transfer coefficient in the tube with baffles under a butterfly shape is better than that for the smooth tube. This baffle shape offers a strong mixing leading to stop the formation of the thermal boundary layer. The higher heat transfer coefficient is obtained with the case (BR $=0.4, \mathrm{PR}=1$ and $R e=8000$ ), where the Nusselt number value for this case is higher by about $40 \%$, compared with the smooth tube. Hence, the heat transfer coefficient in the tube with baffles under a butterfly shape is better than that for the smooth tube. This baffle shape offers a strong mixing leading to stop the formation of the thermal boundary layer. 


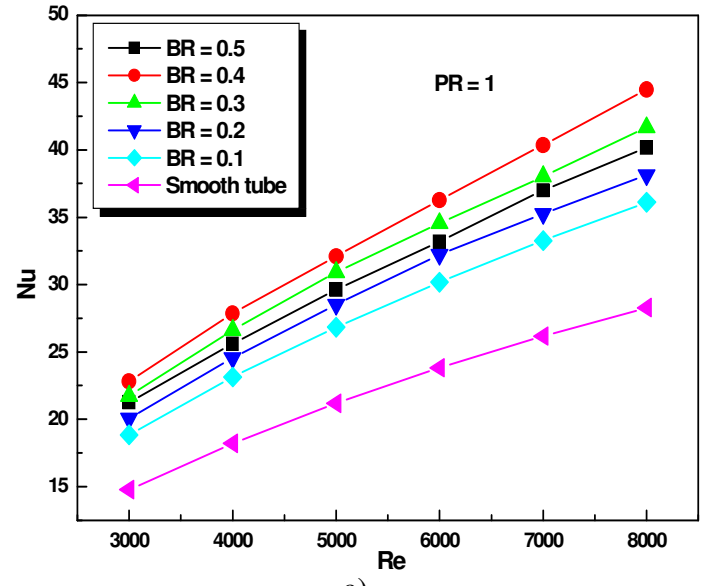

a)

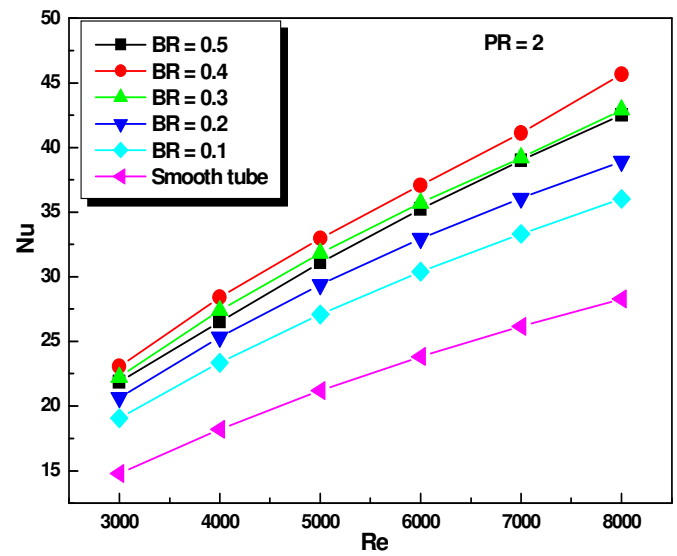

b)

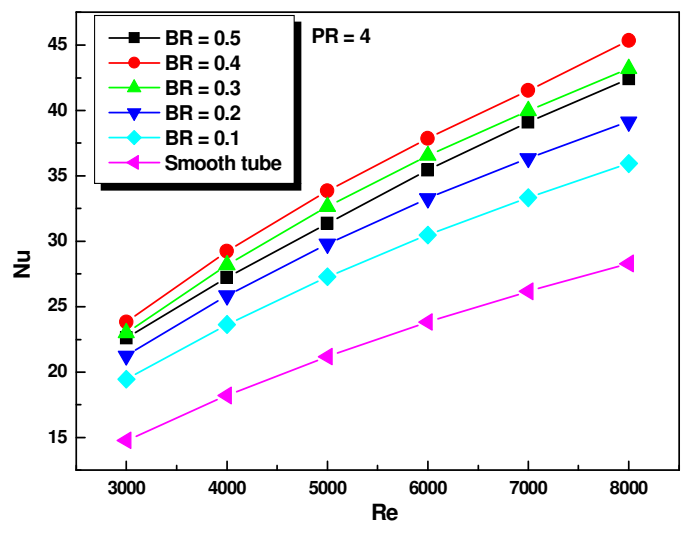

c)

Fig. 7 Variations of $\mathrm{Nu}$ versus $\mathrm{Re}$, a) $\mathrm{PR}=1$, b) $\mathrm{PR}=2$ c) $\mathrm{PR}=4$

\subsection{Friction Factor}

Habitually and because of the change in the flow direction and the velocity fluctuations near the wall, the augmentation of the heat transfer coefficient results an increase of the friction factor. Effects of PR and BR on the friction factor are shown in Fig. 8(a-c). As observed, the friction factor decreases with the decrease of the blockage ratio (BR) and the increase of Reynolds number $(R e)$ and the pitch ratio (PR). This is due to the dynamic pressure dissipation caused by the higher surface area and the act of the reverse/swirl flow. At $R e=3000$ and for the optimal value of pitch ratio $(P R=1)$, the heat transfer enhancements with the following values of the blockage ratio $(\mathrm{BR}=$
$0.1,0.2,0.3,0.4$ and 0.5$)$ are about $33 \%, 66 \%, 80 \%, 87 \%$ and $85 \%$ above the smooth tube, respectively.

However, at $R e=3000$, the baffle case with $\mathrm{BR}=0.4$ and $\mathrm{PR}=1$ gives the greatest value of friction factor. For this case, $f$ is greater by about $87 \%$ compared with the smooth tube. This is due to the blockage of flow and its contact with the large surface of baffle $(\mathrm{BR}=0.4)$.

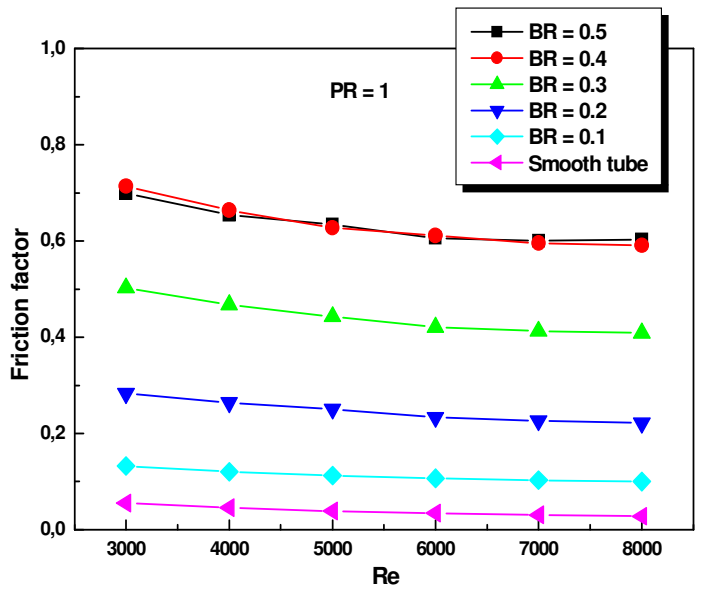

a)

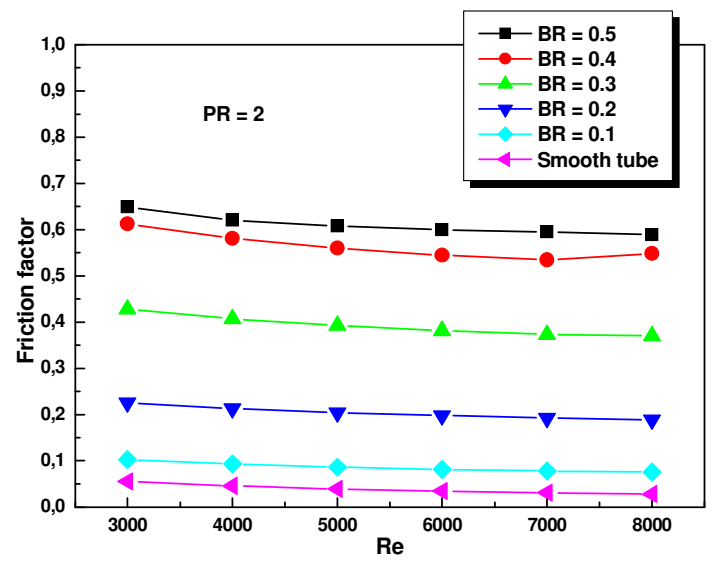

b)

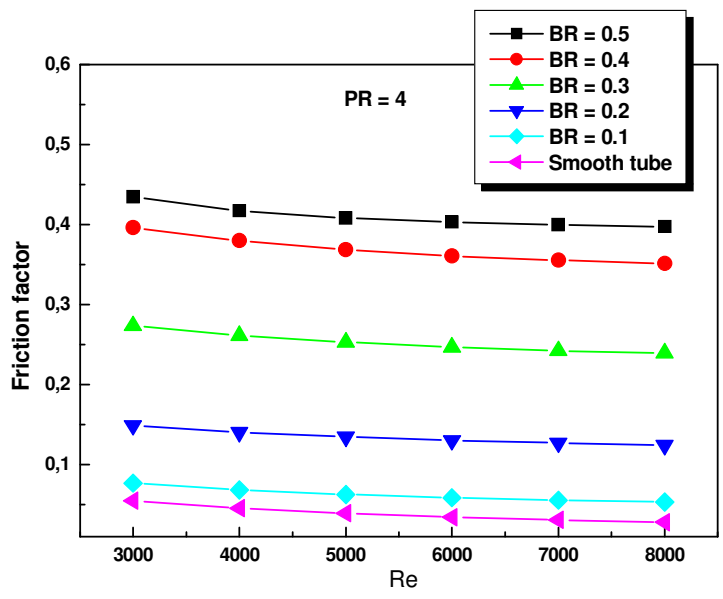

c)

Fig. 8 Variations of friction factor vs. Reynolds Numbers, a) PR = $1, \mathrm{~b}) \mathrm{PR}=2$, c) $\mathrm{PR}=4$ 


\subsection{Evaluation of Thermal Performance}

Fig. 9 shows the variation of the thermal enhancement factor $(\eta)$ vs. Reynolds number for different baffle arrangements. The enhancement factor tends to increase with the rise of Reynolds number for various $\mathrm{BR}$ and PR values. Except the case with $\mathrm{BR}=0.5$, the thermal enhancement factor is higher than the unit for the others cases, indicating that the use of butterfly baffles is advantageous and efficient than the smooth tube. As remarked, the baffle with $\mathrm{BR}=0.1$ and $\mathrm{PR}=$ 4 presents the maximum enhancement factors $(\eta)$ are about 1.7 to 1.5 with the rise of $R e$.

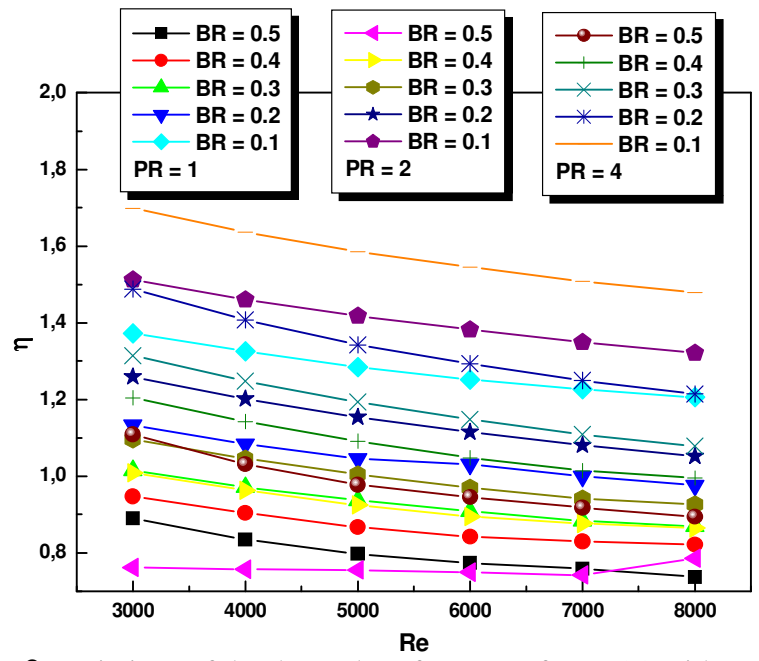

Fig. 9 Variations of the thermal performance factor $(\eta)$ with Re for various $B R$ and $P R$

\section{CONCLUSIONS}

The present paper summarized results of numerical investigations of the fluid flow and heat transfer characteristics in a tubular heat exchanger fitted with series of butterfly baffles as a new design under different blockage and pitch ratios. The numerical analyses were performed for a turbulent flow where the Reynolds number was ranging from 3000 to 8000 . The obtained results have shown that the butterfly baffles ensure a good mixing of flows and intensifies the circulation of fluid particles inside the tube. The baffle with $\mathrm{BR}=0.1$ and $\mathrm{PR}=4$ give the highest enhancement factors $(\eta)$ which are about 1.7 to 1.5 with the rise of Re. Therefore, this case merits to be used in designing the tubular heat exchangers.

\section{ACKNOWLEDGEMENTS}

The authors thank Dr. Yuwen hang for all discussions and technical assistance

\section{NOMENCLATURE}

A Convection heat transfer area, $\mathrm{m}^{2}$

$B R \quad$ Blockage Ratio $\mathrm{BR}=e / D$

$D_{h} \quad$ Hydraulic diameter $\mathrm{m}$

$F \quad$ Friction factor

$G_{K} \quad$ Turbulent kinetic energy production

$h \quad$ Heat transfer coefficient, $\mathrm{W} \mathrm{m} \mathrm{m}^{2} \mathrm{~K}^{-1}$

$k \quad$ Turbulent kinetic energy, Joule

$k_{\mathrm{f}} \quad$ Thermal conductivity, $\mathrm{W} \mathrm{m} \mathrm{m}^{-1} \mathrm{~K}^{-1}$

$L \quad$ Channel length, $\mathrm{m}$

$\mathrm{Nu} \quad$ Nusselt Number

$P \quad$ Space between two successive baffles M

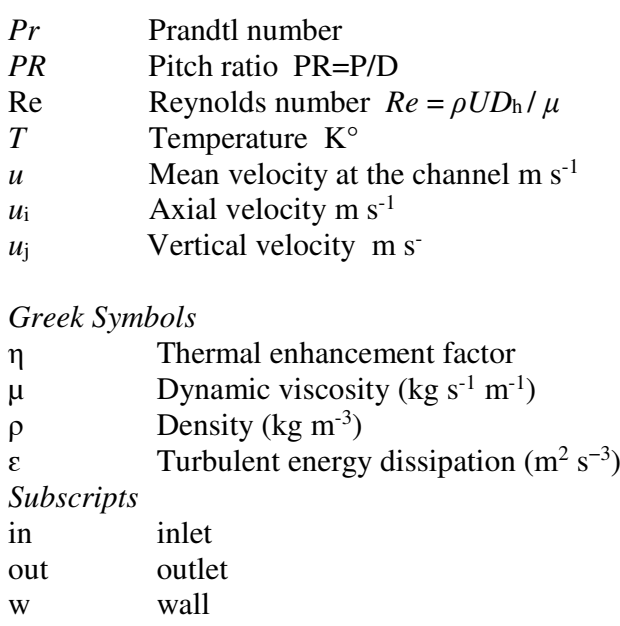

\section{REFERENCES}

Promvonge, P., Khanoknaiyakarn, C., Kwankaomeng, S., and Thianpong, C., 2011, "Thermal Behavior in Solar Air Heater Channel Fitted with Combined Rib and Delta-Winglet," Int. Commun Heat Mass Transfer, 38, $749-756$.

http://dx.doi.org/10.1016/j.icheatmasstransfer.2011.03.014.

Kumar, A., Kim, M.H., 2015, "Convective Heat Transfer Enhancement in Solar Air channels," Appl. Therm. Eng, 89, 239-261. http://dx.doi.org/10.1016/j.applthermaleng.2015.06.015.

Giovanni, T., 2004, "Heat Transfer in Rectangular Channels with Transverse and V-Shaped Broken Ribs," Int. J. Heat Mass Transfer, 47, 229-243.

http://dx.doi.org/10.1016/S0017-9310(03) 004 14-9.

Al-Sammarraee, M., Chan, A., 2009, "Large-Eddy Simulations of Particle Sedimentation in a Longitudinal Sedimentation Basin of a Water Treatment Plant," Part 2: "The Effects of Baffles," Chem. Eng. J, 152, 315-332. http://dx.doi.org/10.1016/j.cej.2009.04.062.

Han, J.C., Zhang, Y.M., Lee, C.P., 1991, "Augmented Heat Transfer in Square Channels with Parallel, Crossed and V-Shaped angled Ribs," ASME Journal of Heat Transfer, 113, 590-596.

http://dx.doi.org/10.1115/1.2910606

Han, J.C., Zhang, Y.M., Lee, C.P., 1992 ," Influence of Surface Heat Flux Ratio on Heat Transfer Augmentation in Square Channels with Parallel, Crossed and V-Shaped Angled Ribs," ASME Journal of Turbo-machinery, 114, 872-880.

Torii, K., Kwak, K.M., Nishino, K., 2002," Heat Transfer Enhancement Accompanying Pressure-Loss Reduction with Winglet Type Vortex Generators for Fin Tube Heat Exchangers, "Int. J. Heat Mass Transfer, 45, 3795-3801.

http://dx.doi.org/10.1016/S0017-93 10 (02)00 080-7.

Wang, C.C., Lo, J., Lin, Y.T., and Wei, C.S., 2002, "Flow Visualization of Wave Type Vortex Generators Having Inline Fin-Tube Arrangement," Int. J. Heat Mass Transf., 45, 1933-1944. http://dx.doi.org/10.1016/S0017-93 10 (01) 00 289-7.

Promvonge, P., Koolnapadol, N., Pimsarn, M., and Thianpong, C., 2014, "Thermal Performance Enhancement in a Heat Exchanger Tube Fitted with Inclined Vortex Rings," Appl. Therm. Eng, 62(1), 285-292. http://dx.doi.org/10.1016/j.applthermaleng.2013.09.031. 
Promvonge, P., Sripattanapipat, S., Kwankaomeng, S., 2010 ," Laminar Periodic Flow and Heat Transfer in Square Channel with $45^{\circ}$ Inline Baffles on Two Opposite Walls," Int. J. Therm. Sci, 49, 963-975. http://dx.doi.org /1 0.1016/j.ijthermalsci.2010.01.005.

Kwankaomeng, S., Jedsadaratanachai, W., Promvonge, P., 2010, "Laminar Periodic Flow and Heat Transfer in Square Channel with $30^{\circ}$ Inclined Baffles," PEA-AIT Int. Conf. Energy Sus, Dev. Issues and Strategies, Thailand.

Promvonge, P., Tamna, S., Pimsarn, M., Thianpong, C., 2015, "Thermal Characterization in a Circular Tube Fitted with Inclined Horseshoe Baffles," Applied Thermal Engineering, 75, 1147-1155. http://dx.doi.org/10.1016/j.applthermaleng.2014.10.045.

Islam, A.K.M.S., Barna, S.F., Amin, M.R., Bhuiyan, A.A., and Banna M.H., 2010, "Mixed Convection and Entropy Generation Characteristics Inside a Porous Cavity with Viscous Dissipation Effect," ASME International Mechanical Engineering Congress. http://dx.doi: 10.1115/IMECE2009-10883

Bhuiyan, A.A., Banna, M.H., Barna, S.F., Amin, M.R., Islam A.S., 2016, "Numerical Modeling of Thermal Characteristics in a Micro Structure Filled Porous Cavity with Mixed Convection," Int. J. Heat Mass Transfer, 93, 464-476.

http://dx.doi.org/10.1016/j.ijheatmasstransfer.2015.10.004.
Sahel, D., Ameur, H., Benzeguir, R,. Kamla, Y., 2016," Enhancement of Heat Transfer in a Rectangular Channel with Perforated Baffles," Appl. Therm. Eng, 101, 156-164.

http://dx.doi.org/10.1016/j.applthermaleng. 2016.02.136.

FLUENT6.0User'sGuide,2001,V2

http://www.ansys.com/Products/Fluids/ANSYS-Fluent.

Dittus, F.W., Boelter, L.M.K., 1930, Heat Transfer in Automobile Radiators of the Tubular Type, University of California Publications on Engineering, 2 443, Berkley.

Gnielinski, V., 1976,"New Equations for Heat and Mass Transfer in Turbulent Pipe Flow and Channel Flow," Int. Chem. Eng, 16, 359-368.

Moody, L.F., 1944, "Friction Factors for Pipe Flow," Trans. ASME, 66 671-684.

Zhang, J.F., He, Y.L., Tao, W.Q., 2009, "3D Numerical Simulation on Shell-and-Tube Heat Exchangers with Middle-Overlapped Helical Baffles and Continuous Baffles - Part I: Numerical Model and Results of Whole Heat Exchanger with Middle-Overlapped Helical Baffles," Int. J. Heat Mass Transfer, 52, 5371-5380. http://dx.doi.org/10.1016/i.iiheatmasstransfer.2009.07.006 